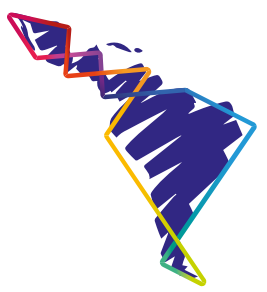

\title{
La inversión de la concepción de los Derechos Humanos y su uso en América Latina
}

\author{
The inversion of the conception of \\ Human Rights and its use in Latin \\ America
}

\section{A inversão da concepção de Direitos Humanos e seu uso na América Latina}

\section{Dan Abner Barrera Rivera}

\begin{abstract}
Resumen
En el presente artículo se realiza una aproximación a la formulación que hizo Occidente del concepto de derechos humanos; se trata de una concepción burguesa que invierte el significado de los derechos humanos, donde la prioridad es la propiedad privada. Para comprender y explicar esa inversión, se recurre a algunos trabajos de Franz Hinkelammert, uno de los pensadores que más ha estudiado el tema. Luego se plantea que esa inversión de los derechos humanos tiene estrecha relación con la democracia capitalista y neoliberal; se expone cómo en América Latina, las democracias burguesas son la plataforma adecuada, para la aplicación de la economía de mercado, cuya concepción de derechos humanos consiste en esa visión invertida, que, en nombre de la libertad de empresa, la democracia y de esa formulación de derechos humanos, niega, reduce, quita, desaprueba y viola derechos humanos. Se muestra a modo de contraste esta situación con los logros obtenidos por algunos gobiernos de izquierda durante los tres primeros lustros del siglo XXI, y se concluye exponiendo lo que Cuba -un país
\end{abstract}

Recibido: 23-8-2020 - Aceptado: 13-5-2021

1 Peruano-costarricense. Licenciado en Estudios Latinoamericanos y en Teología. Máster en Derechos Humanos de la Universidad Estatal a Distancia. Realizó estudio de posgrado en Ciencias Políticas. Académico del Instituto de Estudios Latinoamericanos de la Universidad Nacional de Costa Rica, donde es profesor e investigador. Ha participado con ponencias en coloquios y congresos nacionales e internacionales. Autor de varios artículos en revistas académicas latinoamericanas. Sus áreas de interés en investigación son: pensamiento latinoamericano, derechos humanos, religión, medios de comunicación. Correo electrónico: dan. barrera.rivera@una.cr (D) https://orcid.org/0000-0003-3441-5899 
bloqueado económicamente-, ha hecho por los derechos humanos, en una perspectiva opuesta a la visión burguesa de los derechos humanos.

Palabras claves: Derechos humanos; Cuba, América Latina; mercado; capitalismo.

\begin{abstract}
In the present article an approximation will be made to the formulation fashioned by the West of the concept of human rights; it is a bourgeois conception that inverts the meaning of human rights, where the priority is private property. To understand and explain this reversal, resource is made to some works by Franz Hinkelammert, one of the premier thinkers on the subject matter. Then it is suggested that this inversion of human rights is closely related to capitalist and neoliberal democracy; it is exposed how in Latin America bourgeois democracies are the appropriate platform for the application of the market economy, whose conception of human rights consists of such inverted vision that, in the name of freedom of enterprise, democracy and of this formulation of rights human rights, denies, reduces, removes, disapproves of and violates human rights. This situation is shown by way of contrast with the achievements had by some leftist governments during the first three decades of the 21 st century and it concludes by exposing what $\mathrm{Cuba}$ - an economically blocked country-has done for human rights, from a perspective opposite to that of the bourgeois vision of human rights.
\end{abstract}

Keywords: Human rights; Cuba, Latin America; Market; Capitalism.

\title{
Resumo
}

Neste artigo é feita uma abordagem da formulação feita pelo Ocidente do conceito de direitos humanos; é uma concepção burguesa que inverte o significado dos direitos humanos, onde a prioridade é a propriedade privada. Para entender e explicar essa reversão, são utilizadas algumas obras de Franz Hinkelammert, um dos pensadores que mais estudou o assunto. Também, sugere-se que essa inversão dos direitos humanos está intimamente relacionada à democracia capitalista e neoliberal; expõe-se como na América Latina as democracias burguesas são a plataforma adequada para a aplicação da economia de mercado, cuja concepção de direitos humanos consiste naquela visão invertida que, em nome da liberdade de empresa, da democracia e daquela formulação de direitos humanos, nega, reduz, remove, desaprova e viola os direitos humanos. Esta situação se contrapõe às conquistas de alguns governos de esquerda durante as três primeiras décadas do século XXI e se conclui expondo o que Cuba - um país economicamente bloqueado - fez pelos direitos humanos, numa perspectiva oposta à da visão burguesa dos direitos humanos.

Palavras-chave: Direitos humanos; Cuba; América Latina; Mercado; Capitalismo. 


\section{Introducción}

¿Por qué hoy en los países democráticos de América Latina se plantea con más intensidad el tema de los derechos humanos? Una respuesta sencilla sería afirmar que hoy más que nunca los derechos humanos son ignorados, desprotegidos, suprimidos y violados. No es que se habla mucho de los derechos humanos porque se haya avanzado en la garantía y protección de ellos, sino porque cada vez están más ausentes. Una situación que llama en especial medida la atención y se muestra cada vez más evidente, es que, en nombre de los derechos humanos, se realizan acciones y se toman decisiones con el objetivo de negar, atentar, irrespetar, restar y quitar derechos humanos; es decir, se invocan los derechos humanos, con el fin de violarlos.

En la historia de América Latina han sido los gobiernos de derecha los que han recurrido a ese uso falaz de los derechos humanos cuando han aplicado medidas económicas perjudiciales para las condiciones sociales y humanas de los pueblos; pero la originalidad de la instrumentalización del tema de los derechos humanos se encuentra, en la política exterior impulsada por los diferentes gobiernos de los Estados Unidos hacia Latinoamérica (y también hacia algunos países de Medio Oriente). Los Estados Unidos, desde su condición de país hegemónico y posicionándose como árbitro del bien y del mal, decide unilateralmente en cuál país se violan los derechos humanos y, en nombre de esos derechos humanos y de la democracia, va de prisa a "rescatarlos".

Uno de los casos que llama más la atención, es la guerra económica, financiera, comercial, cultural, política y mediática que se realiza desde hace varias décadas contra Cuba en nombre de los derechos humanos (basta escuchar el discurso que con los años se repite por parte de la representación de los Estados Unidos en la Asamblea General de la ONU contra Cuba). Hasta el día de hoy la Revolución cubana es considerada desde los intereses dominantes de los Estados Unidos, una dictadura, hecho por el cual se le señala como un país que viola los derechos humanos; dicha visión ha sido naturalizada desde algunos poderes hegemónicos como el gobierno norteamericano, los grandes medios de comunicación, la industria cultural contrarrevolucionaria, la Organización de Estados Americanos (OEA) y no pocas ONG que trabajan en derechos humanos.

Esta instrumentalización se hace desde una concepción invertida de estos derechos, visión creada por Occidente con intereses capitalistas; en otras palabras, se trata de una perspectiva que niega los derechos humanos en nombre de los propios derechos humanos. Uno de los pensadores que mejor ha estudiado esta inversión 
interesada que Occidente tiene de la concepción de los derechos humanos es el filósofo, teólogo y economista Franz Hinkelammert.

El presente artículo se propone explicar cómo se encuentra presente esa concepción invertida de los derechos humanos en los países democráticos de América Latina y el uso interesado que se hace de ella con el fin de negar los logros que la Revolución cubana tiene en materia de derechos humanos. Para ello, primero explicamos las tesis centrales que Hinkelammert tiene respecto a la inversión ya mencionada que realiza Occidente. Después, se procede a mostrar cómo los gobiernos de derecha en América Latina relacionan temas vinculados a los derechos humanos con la democracia capitalista y neoliberal, así como la forma y el motivo por el cual, en esos gobiernos, las organizaciones sociales se movilizan para reclamar derechos. Luego, se presenta un análisis de cómo funciona la economía capitalista, en la que el dios mercado exige sacrificios humanos y ambientales para, posteriormente, contrastarlo con la realidad que experimentan otros países de la región, en los que algunos gobiernos de izquierda garantizaron y avanzaron en la defensa de derechos. El artículo termina con una exposición sobre los alcances que la Revolución cubana ha tenido en algunas áreas de los derechos humanos, lo cual sirve para terminar de describir esa inversión burguesa, occidental y capitalista que se hace de los derechos humanos en América Latina.

\section{Franz Hinkelammert y la inversión de los derechos humanos}

En la mayoría de sus libros Franz Hinkelammert aborda el tema de cómo Occidente ha invertido la concepción de los derechos humanos; a continuación, se realiza una síntesis de sus ideas centrales, para lo cual se recurre a algunos de sus textos principales.

Hinkelammert (2018) plantea que "la historia de los derechos humanos modernos es al mismo tiempo la de su inversión, la cual transforma la violación de estos mismos derechos humanos en un imperativo categórico de la acción política" (p.106). Los derechos humanos son formulados en el siglo XVIII. Dicha enunciación es hecha poniendo la propiedad privada por encima del ser humano, es esta la idea principal. Cuando el filósofo inglés John Locke (1632-1704) formula esta concepción sobre derechos humanos, lo hace desde un contexto y pensamiento, donde prepondera la propiedad privada. No son los esclavos, las mujeres, los obreros, los trabajadores de ese tiempo quienes formulan esta concepción (la mayoría de ellos no solo no tenían propiedades, sino que estas eran propiedad de otros). "Locke declara los derechos humanos burgueses universalmente, para en seguida sostener, que aquellos que no aceptan de buena gana estos derechos, son animales salvajes frente a los cuales estos derechos no valen" (Hinkelammert, 2007, p.232). Esa enunciación de derechos 
humanos es concebida desde una posición del propietario (beneficiado) de bienes (tierras, casas, esclavos, etc.), por lo cual se trata de una perspectiva individualista en cuanto evita o ignora señalar los deberes que tienen las personas respecto a los otros; no contiene ninguna responsabilidad con la esfera social o colectiva, como el derecho a la equidad, la justicia, la afirmación de la humanidad, la solidaridad internacional, la paz entre los pueblos, el desarrollo de los pueblos y la soberanía, sino que, por el contrario, se trata de una concepción desde la condición de quienes poseen bienes y, por ende, meramente beneficia sus intereses.

Desde este pensamiento, la prioridad no es la dignidad humana, sino el sistema de propiedad, el cual se considera como una referencia total; así, los derechos humanos son absorbidos -encapsulados y obnubilados- por el pensamiento de la propiedad individualista. Cuando el pensamiento de propiedad es colocado como centro, la referencia a la dignidad humana queda por fuera y las relaciones humanas se convierten en relaciones de propiedad, en una especie de contrato de compraventa (Hinkelammert, 2012a).

Con este pensamiento nace y se desarrolla la democracia liberal. Esta, tiene una concepción de ser humano sin dimensión humana, no contiene una valoración de lo humano puesto que lo fundamental es la propiedad. A raíz del surgimiento en el siglo XVIII de una democracia liberal formulada baja esa concepción de derechos humanos que niega la dignidad humana, en el siglo XIX -y en adelante- van a surgir diversos movimientos sociales de emancipación que se enfrentarán a dicha visión de los derechos humanos, es decir, a la negación de la vida. Entre estos movimientos se encuentran el movimiento obrero, los movimientos de emancipación de los esclavos, las mujeres, la emancipación de los pueblos indígenas, los campesinos, las colonias, las culturas y la naturaleza. Para Hinkelammert, la lucha de emancipación de todos estos movimientos puede entenderse en cuanto reivindican la dignidad humana: no se trata de movimientos que persigan algún tipo de propiedad. Refiriéndose a este fenómeno social del siglo XIX y XX, sostiene:

Se trata de un nuevo movimiento que es humanismo del sujeto viviente frente a la reducción del humanismo burgués al humanismo de propietarios en una sociedad de mercado, que ya tenía la tendencia a reconocer un solo derecho como derecho humano: el derecho de propiedad. (Hinkelammert, 2017, p.29)

Esas luchas de emancipación de los movimientos sociales se basan en el principio fundamental de que los únicos que tienen derechos humanos son las personas, no las instituciones o las propiedades; solo el ser humano posee dignidad, en cambio las cosas, las propiedades o instituciones no la tienen. En base a esto, Hinkelammert (2012a) sostiene que es inaceptable el hecho de que se quiera defender que 
el derecho de propiedad es un derecho natural, argumento que no puede sostenerse debido a que la propiedad no es un ser humano. Si la propiedad privada o la institución tuvieran un derecho absoluto, no podría haber ningún discernimiento contra esa propiedad privada porque esta sería elevada a un estatus de sagrada con lo cual se le habría dado un carácter semejante a la dignidad humana; no sería posible tocarla ni intervenirla. Este pensamiento se hace cada vez más evidente en las políticas neoliberales cuando se presenta a las instituciones privadas como las salvadoras de la sociedad y, por lo tanto, se las exhibe como entes perfectos, inmunes y sagrados. Desde esa concepción y lógica del mercado -convertido en dios-, no se discute lo que son y lo que hacen las instituciones privadas, y tampoco se acepta que estas sean controladas.

De este modo, cuando algún gobierno intenta cuestionar o regular alguna institución o empresa privada como, por ejemplo, una transnacional minera, se acusa, bajo dichos parámetros, a tal gobierno de ser una dictadura, de irrespetar los derechos de la propiedad privada y de atentar contra la libertad de empresa. La idea que la ideología neoliberal ha logrado posicionar desde esa formulación de derechos humanos (de propiedad privada) es que no se le debe intervenir. Ante esa concepción el autor señala:

El derecho humano consiste en derechos que corresponden al ser humano como ser corporal integral y que incluye el derecho de vivir. Expresado en lenguaje jurídico, se trata de derechos de personas naturales, a diferencia de las personas jurídicas. Las personas jurídicas no tienen derechos humanos, porque no son seres humanos, solamente las personas naturales los tienen. Las grandes sociedades anónimas son personas jurídicas, como tales no pueden tener ninguna clase de derechos humanos. (Hinkelammert, 2012a, p.107)

Esa visión invertida les otorga derechos a las grandes corporaciones como si se tratara de personas, por lo cual se las vuelve inviolables, entes que no pueden ser intervenidos. Así, estas pueden seguir haciendo sus negocios, sacrificando a las personas y a la naturaleza. Desde esa perspectiva la persona humana es reducida a un individuo y se le equipara con las personas jurídicas colectivas, con lo cual el ser humano pierde su condición de persona, de ser corporal; si las personas jurídicas y colectivas tienen derechos humanos, entonces los derechos de las personas humanas quedan eliminados. Sobre esta cuestión, Hinkelammert pregunta:

¿Tiene Microsoft derechos humanos? ¿O tienen los seres humanos derechos humanos cuya validez hace falta imponer frente a Microsoft? ¿Tiene la CNN derechos humanos o tienen los seres humanos derechos humanos frente a la CNN? En su 
lógica los derechos de personas colectivas devoran los derechos humanos de la persona humana como ser corporal y ser natural -parte de la naturaleza-. Tenemos que enfrentar un conflicto entre derechos humanos y derechos colectivos de instituciones y asegurar que los derechos humanos sean respetados por esas personas jurídicas y colectivas. (Hinkelammert, 2012b, p.26)

Esta postura permite que en el actual proceso de globalización los neoliberales hablen sin pudor de la necesidad de proteger la propiedad privada como si hablasen de un ser humano con derechos. La totalización de los mercados anula de manera lenta pero segura los derechos humanos de las personas. Mientras los movimientos sociales luchan por emanciparse de esa perspectiva de derechos humanos que se aplica en las democracias capitalistas, el sistema capitalista no cesa en realizar ajustes para seguir protegiendo la propiedad privada a cualquier costo; el mercado demoniza y luego sanciona a quienes se oponen a esa lógica.

En este tipo de situaciones, los medios de comunicación juegan un papel crucial porque satanizan los movimientos sociales y censuran a los líderes políticos y sociales que defienden los derechos humanos, los presentan como monstruos, como bestias salvajes que deben ser eliminadas (Hinkelammert, 2018). Así, la inversión de la concepción de los derechos humanos y su aplicación se hacen evidentes. Desde esta visión, Estados Unidos desarrolla su "preocupación" por los derechos humanos en el mundo, tal y como lo demuestra la historia de América Latina; son ellos quienes deciden en qué países se "violan" los derechos humanos $\mathrm{y}$, curiosamente, estos países perjudicados, la mayoría de las ocasiones, poseen abundantes riquezas naturales o se trata de gobiernos de izquierda. De esta manera, en nombre de los derechos humanos, los Estados Unidos termina por acabar con los que comparten su pensamiento. Sobre esto, Hinkelammert dice:

Creo que constantemente se usan los derechos humanos en contra de los mismos derechos humanos. Guerras en cuya consecuencia todo es destruido, se declaran "intervenciones humanitarias", que pretendidamente tienen el fin de garantizar los mismos derechos humanos. Con eso se transforman los derechos humanos en el imperativo categórico de violarlos. Hoy precisamente los EE. UU. promueven a los ojos del mundo entero esta política, que ya antes habían determinado las colonizaciones. (Hinkelammert, 2012a, p.110)

Estas son las ideas centrales de Hinkelammert sobre la inversión de los derechos humanos que es creada y asumida por Occidente, idea que toma, como ya se explicó, un punto de partida errado e interesado, pues actúa en contra de la dignidad de las personas. Occidente universaliza esa visión y la armoniza (asocia) con la democracia burguesa occidental, a la vez que se opone a cualquier pensamiento 
contrario. En la historia reciente es posible hallar una gran cantidad de casos donde, en nombre de la democracia burguesa y los derechos humanos, se realizan guerras, invasiones, bloqueos, saqueos, homicidios, torturas, etc.

\section{Derechos humanos, democracia y gobiernos neoliberales en América Latina}

Cuando en América Latina los políticos de derecha se refieren a los derechos humanos lo relacionan con conceptos como democracia, paz, libertad, elecciones, entre otros (Gallardo, 2007). Expresiones como estas indican que hay una difundida creencia que, por el solo hecho de que un país se reconozca nominalmente "democrático", se trata de una nación que protege los derechos humanos.

Sin embargo, los países, cuyos gobiernos se reconocen democráticos o dicen ser más democráticos que otros, no necesariamente muestran avances en materia de derechos humanos, sino todo lo contrario, tal y como lo demuestra la historia de América Latina. Con esto, no se hace referencia a las dictaduras militares que plagaron nuestros países de cientos de miles de desaparecidos, torturados y asesinados con el apoyo de los Estados Unidos, sino a los países, autodenominados democráticos, puesto que realizan elecciones libres periódicamente, dicen garantizar la libertad de expresión, predican la paz y condenan la guerra.

Por su parte, los medios de comunicación asumen un papel relevante en la ideologización del tema, porque, por un lado, encomian a esos países que se denominan democráticos (no importa si en la realidad estos violan los derechos humanos de sus poblaciones) y, por el otro, cuestionan o critican a los gobiernos de izquierda, afirmando que estos no son democráticos y que sus gobiernos no respetan los derechos humanos. Se presenta, entonces, una visión un tanto maniquea de la realidad, donde ser gobierno de derecha garantizaría la democracia y el respeto a los derechos humanos (Vargas, 2018) y ser gobierno de izquierda trae consigo inestabilidad democrática y el irrespeto de los derechos humanos (Boron, 2019).

Al respecto, resulta interesante lo que afirma Sánchez (2012) cuando plantea que "los reflejos condicionados por los medios establecen que quienes asesinan a sangre fría, orquestan golpes de Estado, encarcelan inocentes y legalizan la tortura son la más sólida democracia de nuestra época" (p.35).

Esta visión suele manifestarse en América Latina de manera más transparente cada vez que se realizan elecciones presidenciales; en estos procesos, al candidato o candidata que por primera vez ingresa a la lid electoral y no pertenece a un partido tradicional (de derecha), se le somete a un escrutinio público mediático para saber 
cuál es su tendencia ideológica. Dos ejemplos de esto son los exámenes severos que les hicieron algunos medios de comunicación a José María Villalta Flores, candidato por el Partido Frente Amplio a la presidencia de Costa Rica en 2014 (CB24, 2013), y a Verónika Mendoza Frisch, candidata por el Frente Amplio a la presidencia de Perú en 2016 (Pc peruano, 2016). El sistema democrático capitalista, burgués y neoliberal solo acepta como candidatos -y los aprueba- a quienes no distorsionen el orden establecido, es decir, a quienes no tengan simpatía con ideales políticos de izquierda o no tengan algún acercamiento con los gobiernos de izquierda. De este modo, distanciarse de ellos o criticarlos, garantizaría su "estampa democrática" y aseguraría que el país se mantenga con "buena salud democrática". En América Latina, con el afán de salvaguardar la democracia, los gobiernos niegan el acceso al poder al que es "diferente", en este caso, al que es considerado de izquierda:

La región aparenta considerar "natural" que las instituciones democráticas no puedan albergar gobiernos "comunistas" en el sentido lato de "distintos y repugnantes" con que se ha empleado el término en América Latina. Así, en nombre de la defensa de "la" democracia se niega su ejercicio por los "diferentes", no siempre demasiado interesados en testimoniar estos valores. (Gallardo, 2005, p.252)

Ha sido recurrente que los medios de comunicación interroguen a candidatos con el propósito de saber si poseen alguna simpatía con los presidentes de izquierda de América Latina (Fidel Castro, Hugo Chávez, Raúl Castro o Nicolás Maduro). Ejemplos de esto, son los casos de Andrés López Obrador en México (Univisión Noticias, 2018), de Nayib Bukele en El Salvador (Así Estamos, 2018), de Gustavo Petro en Colombia (Univisión Noticias, 2018), de Rafael Correa Delgado en Ecuador (Rondón, 2017), entre otros. En cambio, los medios en cuestión no suelen indagar en estas cuestiones cuando se trata de personajes como Álvaro Uribe, Alberto Fujimori, Enrique Peña Nieto, Mauricio Macri, Sebastián Piñera o Jair Bolsonaro.

Resulta palmario, tomando en consideración lo anterior, que el candidato simpatizante con estos últimos presidentes (de derecha todos) posee garantía para la continuidad de la democracia y el respeto a los derechos humanos de acuerdo con la visión de la democracia burguesa capitalista. Por el contrario, tener acercamiento o simpatía con algún presidente del primer grupo de mandatarios (de izquierda) significa, con base al escenario planteado, poner en riesgo la salud democrática y la protección de los derechos humanos.

Sin embargo, en realidad resulta que, en estos países denominados democráticos, la protección de los derechos humanos no ha sido una característica positiva. A continuación, tres ejemplos: 1) en Perú, de 1980 a 2000, especialmente en los gobiernos 
de Alberto Fujimori (1990-2000), las ejecuciones extrajudiciales, desapariciones forzadas, secuestros, torturas, asesinatos, lesiones graves, entre otros, marcaron a dicho país, según el Informe Final de la Comisión de la Verdad y Reconciliación (2003): "Dada la información disponible, concluimos que el número total de muertos y desaparecidos causados por el conflicto armado interno peruano se puede estimar en 69,280 personas" (p.13); 2) en México, en el sexenio de Enrique Peña Nieto (2012-2018), las desapariciones forzosas, violencia de género, tortura, ejecuciones, asesinato de activistas sociales, asesinatos de periodistas, aumentaron al extremo en el que aproximadamente cuatro personas eran asesinadas cada hora: "De acuerdo con cifras oficiales, desde que inició este sexenio hasta julio de este año, se han cometido 112 mil 760 homicidios dolosos y 22 mil casos de desaparición” (Guzmán, 2018: párr. 2); y 3) en Colombia, en apenas dos años del gobierno de Iván Duque Márquez, según indicó el Instituto de Estudios para el Desarrollo y la Paz, INDEPAZ (NODAL, 2020), entre el 7 de agosto de 2018 y julio de 2020, han asesinado a 573 líderes sociales y defensores de los derechos humanos. Todo esto, en países conocidos y autonombrados como democráticos.

\section{Las movilizaciones sociales por los derechos humanos}

Los derechos humanos, más allá de hacer referencia a un tema, tratan de la vida misma; es la vida de los seres humanos la que está en disputa, por eso en las últimas décadas ha surgido con gran ímpetu las luchas por su defensa, luchas sociales presentes a largo de América Latina, aunque mayormente presentes en los países con gobiernos de derecha que imponen medidas económicas, a la vez que niegan la dignidad de la vida y pretenden sociedades con seres humanos sin derechos.

Los sectores sociales que se movilizan en estos movimientos en su mayoría pertenecen a poblaciones vulneradas debido a las políticas económicas neoliberales que afectan directamente la vida de sus habitantes (campesinos, educadores, obreros, mujeres, estudiantes, pueblos indígenas, mineros, poblaciones LGBTIQ+, personas sin tierra, personas sin casa, poblaciones afrodescendientes, entre otras).

Mientras los grandes medios de comunicación invisibilizan las luchas de estos sectores sociales, criminalizándolas o censurándolas, existe una amplia infografía de esas luchas en las redes virtuales que revelan los rostros concretos de los diversos grupos que libran batallas por la defensa de sus derechos. Así, dichas luchas se internacionalizan e informan de las necesidades de la gente y, al mismo tiempo, dan a conocer qué agrupaciones participan, qué luchas son las que se presentan, qué costos tienen y cómo son reprimidas por los gobiernos neoliberales. 
En ningún país de América Latina se han observado marchas de protesta por parte de las cámaras empresariales o de los poderes fácticos contra alguna medida económica aplicada por alguno de los gobiernos neoliberales en cuestión, puesto que estos sectores no necesitan pronunciarse en cuanto se trata de gobiernos al servicio de las oligarquías de las cuales forman parte. Las masivas movilizaciones de diversas organizaciones sociales en pro de sus derechos se realizan en esos países llamados democráticos, es ahí donde la gente se organiza para luchar contra las políticas económicas que reduce, niega y viola sus derechos.

\section{La economía de mercado y la negación de los derechos humanos}

En las democracias burguesas y neoliberales, en nombre de la economía de mercado, se reducen los empleos y se despiden trabajadores de las empresas públicas; en nombre del dios mercado se abandona, empobrece y precariza la educación pública, así como aumenta la privatización de la educación en sus distintos niveles, de este modo, toda aquella persona que quiera tener una educación de "calidad" debe pagar por ella, para lo cual se proyectan préstamos bancarios que, muchas veces, no cuentan con regulación del Estado.

En este "altar del mercado" se sacrifica el derecho a la salud para todos, con lo cual crece en América Latina la mercantilización de la medicina, permitiendo recibir atención médica de "calidad" solo a aquellas personas que posean el capital económico suficiente para pagarla. Enrique Dussel (2019) afirma que "el médico es un instrumento del capital, y por eso hay una medicina para las clases altas que pueden pagar y una "medicina masiva" para los que no pueden pagar"; esto significa que estos últimos "por supuesto se mueren antes, aunque la vida haya crecido en cuanto a su duración cuantitativa" (Resumen Latinoamericano, 2019, párr. 13).

El negocio del dios capital convierte el derecho a la salud en una mercancía; hoy en cualquier ciudad o barrio latinoamericano proliferan las farmacias como si fueran panaderías. Desde la lógica del mercado, el objetivo de los oligopolios de la medicina no es curar sino enfermar, crear pacientes dependientes de las drogas patentadas y legalizadas que se publicitan y venden sin restricciones. Para protegerse de esta barbarie, la publicidad advierte: "todo medicamento posee efectos secundarios". El premio nobel de medicina en 1993, Richard J. Roberts, señala que algunos medicamentos que podrían curar del todo una enfermedad no son investigados, por lo cual se pregunta "¿hasta qué punto es válido que la industria de la salud se rija por los mismos valores y principios que el mercado capitalista, los cuales llegan a parecerse mucho a la mafia?". (RT, 2013, párr. 4). Afirma que las empresas dejan de investigar porque "no están tan interesadas en curarle a usted como en sacarle dinero", entonces esa investigación es orientada "hacia el 
descubrimiento de medicinas que no curan del todo, sino que cronifican la enfermedad y le hacen experimentar una mejoría que desaparece cuando deja de tomar el medicamento" (RT, 2013, párr. 4).

En nombre del libre mercado se atenta contra la salud de las personas a través de la comida rápida, conocida también como "comida chatarra" o "comida basura"; sus consumidores defienden que estas son comidas que se ven, huelen y saben sabrosas. Otra cuestión por considerar es el hecho de que existen multinacionales que financian a los científicos para obtener provecho de sus investigaciones: "millones de dólares en contribuciones monetarias realizadas por Coca-Cola influyeron en estudios científicos que restaban importancia al papel que juegan las bebidas azucaradas en la obesidad" (Adelaja, 2020, párr. 1).

En nombre de la libertad de mercado y con la permisividad de estas democracias, las grandes empresas también envenenan la tierra y las aguas subterráneas. Algunas investigaciones han demostrado que enfermedades como la obesidad, la diabetes y el cáncer están directamente relacionadas con los alimentos que ingiere la población, pues las hormonas sintéticas presentes en muchos fertilizantes y pesticidas que tienen contacto con la comida son peligrosas para la salud y no se logran detectar en los análisis toxicológicos con premura, con lo cual se invalida de esta forma el principio de que la 'dosis hace el veneno' (Robin, 2013, párr. 1). ¿Quién se atreve a poner restricciones a la industria de esas hormonas en los pesticidas, insecticidas, plaguicidas o herbicidas? El gobierno que lo hace es catalogado de dictadura, de atentar contra la libertad de empresa, de ahuyentar la inversión privada, de coactar la iniciativa y los buenos negocios de la gente. Tal como dice Gallardo (2007), "democracia" es, desde este punto de vista, sinónimo de capitalismo:

El ideologema que identifica régimen neoliberal con democracia, o que afirma su necesidad mutua, tiene primeramente una finalidad agitativa. "Democracia" resulta hoy un vocablo eulógico o bendito en tanto es sinónimo de capitalismo. Identificar las prácticas neoliberales con la democracia facilita asociar efectos como la concentración de riqueza y poder, la precarización y exclusión de la fuerza laboral, la ausencia generalizada de plenitud, la perdida de horizontes y su reemplazo por medios (la riqueza, por ejemplo) como si fueran buenos o queridos por la mayoría o, al menos necesarios. (Gallardo, 2007, p. 53).

El pensamiento neoliberal esgrime la idea de que la gente es libre para elegir lo que desea, es decir, a nadie se le obliga a comprar esas medicinas, ingerir ese tipo de comida, usar tales insecticidas, etc., pero esta idea es embustera, puesto que no es cierto que la gente tenga la opción de elegir en libertad lo que el mercado le ofrece. Los bienes (productos) que el mercado ofrece para comprar son más 
de lo mismo; lo que no es ofertado por el mercado, no aparece como alternativa de compra. Ni en el mundo de la publicidad, ni en la competencia promovida por el mercado desleal, aparecen los bienes que no son parte de la lógica del capital. ¿Puede acaso competir en el mercado internacional un producto nacional, por ejemplo, el frijol cultivado sin agroquímicos por los campesinos, frente al frijol importado, industrializado y subvencionado por el Estado de un país desarrollado y, por ende, más barato? No puede. Por lo tanto, la idea de que la gente es libre para elegir es engañosa porque nuestras sociedades crecen "educadas" por aparatos ideológicos al servicio del mercado: los medios de comunicación, la escuela, la familia, el Internet de Las Cosas, entre otros; aparatos que inducen, desde la perspectiva del mercado, lo que es bueno consumir (aunque no lo sea) y se los ofrece como saludables, bellos, baratos e indispensables.

De tal forma funciona el mercado; la libertad para los negocios tiene su eje en esa democracia capitalista, cuyos gobiernos neoliberales permiten que se atente contra los derechos humanos y para hacerlo goza del respaldo de las leyes (leyes que matan). Asimismo, los medios de comunicación ("información chatarra") y los profesionales de diversas áreas como la medicina, física, química, economía, ingenierías, entre otras, que trabajan para el mercado, no hablan de los daños generados por la industria, ni de las muertes causadas por este sistema; en todo caso dirán que se trata de muertes naturales, o culpabilizarán al propio ser humano por su supuesta libertad de elegir. De esta forma el dios mercado queda exculpado.

Se evidencia, de tal manera, una estrecha relación entre la democracia burguesa y la economía de mercado, en donde los hombres de negocio han capturado la democracia. Frei Betto (2019) recuerda lo que ya había dicho al respecto el banquero estadounidense David Rockefeller en 1999:

En los últimos años existe una tendencia a la democracia y a la economía de mercado en muchas partes del mundo. Eso ha reducido el papel de los gobiernos, lo que resulta favorable para los hombres de negocios ... Pero la otra cara de la moneda es que alguien tiene que ocupar el lugar de los gobiernos, y el business me parece la institución lógica para hacerlo. (Betto, párr. 1)

De igual forma, en nombre del mercado se persigue y se asesinan personas, ¿cuántos defensores del medio ambiente han sido asesinados y desaparecidos en América Latina en los últimos años? ¿Qué gobierno democrático neoliberal defiende a los que están luchando por los derechos humanos en asuntos ambientales? ¿Alcanza esa concepción invertida y manipulada de los derechos humanos para hacerlo? "Todo lo que se hace dentro del neoliberalismo o teniéndolo como referencia es, por definición, 'democrático"” (Gallardo, 2007, p.53). En este sentido surge la 
interrogante: ¿por qué las personas defensoras de la tierra, como Berta Cáceres y Sergio Rojas -en Honduras y Costa Rica, respectivamente- cuyas vidas estaban siendo amenazadas, no fueron protegidas por los supuestos gobiernos democráticos de los territorios donde se encontraban?

\section{Los derechos humanos y los gobiernos progresistas de América Latina}

Al igual que lo hicieron en otro tiempo contra Cuba (y todavía lo siguen haciendo), los gobiernos de derecha y la gran prensa tratan de ocultar algunos logros obtenidos por los gobiernos de izquierda en América Latina durante los tres primeros lustros del siglo XXI; la gente repite con facilidad lo que las matrices de opinión divulgan: "han sido gobiernos fallidos", aun cuando las evidencias señalan lo contrario. Por ejemplo, la CEPAL (2017, p.89) en el balance realizado sobre el desempeño socioeconómico, entre 2002 y 2014, encontró que los gobiernos de izquierda presentaron resultados positivos, tanto en la reducción de la pobreza como en el cierre de la brecha de la desigualdad. ¿Haber sacado de la pobreza a millones de personas desde la gestión gubernamental de los gobiernos de izquierda es "fallido"?

Si bien esos años coincidieron con los ventajosos precios internacionales de las exportaciones de la región, los presidentes de los países en cuestión, a diferencia de otros gobiernos en el pasado, supieron aprovecharlos; por tanto, en el balance que se hace, se destaca la reducción de la pobreza y la desigualdad. Para los gobiernos de izquierda, la política es el ejercicio del poder en la búsqueda del bien común. La izquierda apuesta por la capacidad transformadora de las políticas públicas y no acepta que sea el mercado quien asuma ese papel, debido a que la dirección que este busca dar es otra. Álvaro García Linera, ex vicepresidente del Estado Plurinacional de Bolivia, menciona que en esos años "los gobiernos progresistas que representaron a la izquierda en América Latina consiguieron que 72 millones de habitantes salieran de la pobreza" (2018, párr. 3).

Aunque se dieron los logros mencionados en materia de derechos humanos, para el bienestar de millones de personas, los pueblos han vuelto a elegir a los candidatos de la derecha cuyos gobiernos atentaron contra sus derechos; los casos más recientes han sido los gobiernos de Jair Bolsonaro, en Brasil; Iván Duque en Colombia; Sebastián Piñera, en Chile; entre otros. Al respecto, la expresidenta argentina, Cristina Fernández, antes de que el Frente de Todos ganara las elecciones el 27 de octubre de 2019, expresó: "Es un tema que me desvela: ¿cómo el ser humano puede cometer esos errores y no darse cuenta de que está atentando contra sus propios intereses?" (Fernández, 2019, p. 554). Sobre esto, resulta importante hacer dos señalamientos que ayuden a comprender en parte por qué sucede este fenómeno: 
1) La implementación y la distribución de las llamadas 'fake news' a través de las redes sociales en el contexto de procesos electorales: estas cada vez juegan un papel más influyente (y a veces determinante) en las campañas políticas, tal fue el caso de la elección de Jair Bolsonaro en 2018 (Benites, 2018). El equipo de campaña del ahora presidente de Brasil utilizó, sin ningún tipo de reparos, las 'fake news' a la hora de abarcar diversos temas, por ejemplo: a) para negar que Bolsonaro denigró alguna vez a gais, negros y mujeres; b) para acusar a Fernando Haddad, candidato del Partido de los Trabajadores (PT), de ser el autor intelectual del supuesto kit gay: "Haddad quiere pervertir a los más pequeños. No es admisible que unos niños de seis años tengan que descubrir tan pronto cómo funciona el aparato reproductor o que puede haber sexo entre niños" (El Confidencial, 2018); c) para atribuirle a Haddad la autoría de un proyecto de ley que autorizaría la legalización de la pedofilia; y d) para asegurar que Adélio Bispo de Oliveira, el hombre que apuñaló a Bolsonaro durante un acto electoral, era afiliado al PT.

Según las encuestas sobre la intención de voto, estas 'fake news' anteriormente mencionadas fueron creídas por la mayoría de la gente (Saccone, 2018). ¿Qué se puede hacer ante esto? Las "fake news" han sido tan efectivas que han logrado instalar, en muchas ocasiones, la mentira como si fuera una verdad. En Argentina "le han hecho creer a las personas que bajándoles los impuestos a los ricos se solucionaban todos los problemas económicos" (Fernández, 2019, p. 563). O cuando los empresarios hablan de flexibilización laboral y convencen a los trabajadores de que 'pagándoles menos, podrán darle más trabajo a la gente'. Asombra que, con este tipo de campañas, la gente sea presa fácil de aceptar la mentira como verdad.

2) El llamado "elemento aspiracional": es el deseo de la gente de querer pertenecer a la clase alta, parecerse o sentirse integrada a ella; las personas apoyan con su voto a los candidatos que les ofrecen aquellos estándares de vida con los que soñaron alguna vez. En Costa Rica, el presidente Oscar Arias Sánchez, en su segundo mandato (2006-2010), con el afán de lograr el apoyo ciudadano y aprobar el Tratado de Libre Comercio entre Estados Unidos, Centroamérica y República Dominicana mediante Referéndum, prometió: "Los que hoy vienen en bicicleta, con el TLC vendrán en motocicleta BMW, y los que vienen en un Hyundai, vendrán en un Mercedes Benz, en esto consiste el desarrollo" (Keith, 2017, párr. 5). Además de otra serie de factores que influyeron en la aprobación del TLC con Costa Rica. Tal "elemento aspiracional" ilustra cómo los políticos utilizan esos anhelos del pueblo para lograr acuerdos económicos en los cuales las personas más pobres resultan ser las más perjudicadas. 
El expresidente de Ecuador, Rafael Correa, hace una evaluación del comportamiento de la gente que salió de la pobreza en América Latina e invita a que la propia izquierda reflexione sobre eso:

Una reflexión profunda que debemos hacer es si la izquierda no es víctima de su propio éxito. Del año 2002 al 2014, época de oro de la izquierda en América Latina, noventa millones de latinoamericanos fueron sacados de la pobreza. Sólo en Brasil cerca de treinta millones, pero ¿dónde estuvieron para defender a Dilma? Una de las hipótesis que debemos con mucho dolor enfrentar, es que esa gente al salir de la clase pobre, al ser no pobre o clase media, ya cambian su visión (...). Empieza a soñar con un estilo de vida como el de Nueva York ... . Es decir, comparado con lo que tenían están mucho mejor, pero comparado con lo que ahora desean (aspiran), están mucho peor y son presa fácil de los cantos de sirena de la derecha y sus medios. (Borges, 2019, párr. 23)

El empleo, la seguridad laboral, la educación, el seguro social, la jubilación, la vivienda, entre otros, son derechos humanos mínimos que los gobiernos democráticos deben garantizar, sin embargo, las políticas neoliberales aplicadas por esos gobiernos atentan contra esos derechos; son sociedades donde el que manda es el mercado, mercado para el cual la prioridad no es garantizar los derechos humanos, sino el capital. Al mercado en cuestión no le importa la vida de las mayorías sociales, no le interesa los derechos humanos de esas personas, ni que los derechos humanos de la gente empobrecida sean violados, puesto que se trata de una preocupación que no es considerada por los defensores de la economía de mercado. El tema central para considerar por el mercado es la búsqueda de buenos negocios, por lo que "el capitalismo convierte en mercancía todo lo que toca, desde el sexo hasta la muerte" (Sánchez, 2012, p.22). Ubieta señala que "Todo puede convertirse en dinero: el amor, la belleza, la fealdad, el dolor, el sufrimiento, la muerte (2014, p.99).

Así, reconocer y asegurar los derechos humanos de los pobres es ir en contra de los 'derechos' del mercado; lo que el mercado posee son intereses creados, ganancias del capital realizadas y amparadas por las leyes. El mercado no posee vida; su objetivo es competir, ganar, acumular, explotar, excluir, sacrificar a los seres humanos y a la naturaleza en pro de sus beneficios económicos; el mercado puede destruir el ambiente, saquear las riquezas naturales, contaminar los ríos, los mares, el aire y la tierra, crear alimentos transgénicos y producir medicinas, todo bajo el presupuesto de sus ideales. Hinkelammert menciona:

Desde el punto de vista de las empresas transnacionales, los derechos humanos, como derechos de seres humanos corporales, no son más que distorsiones del 
mercado. Ellas operan y calculan a nivel mundial, y para ellas el mundo entero es el espacio en el cual aparecen las distorsiones del mercado. Su exigencia de apertura para los flujos financieros y de mercancías, de disolución del Estado en sus funciones económicas y sociales y de flexibilización del trabajo, son consecuencias de estas operaciones mundiales. (Hinkelammert, 1999, p.243)

Pareciera una 'fake new', pero no lo es: en 2012 el Fondo Monetario Internacional alertaba del riesgo financiero que suponía el envejecimiento de la población: "los ancianos viven demasiado y es un riesgo para la economía mundial”, por lo tanto, creía necesario "aumentar la edad de jubilación y de las contribuciones a los planes de pensiones con recortes de las prestaciones futuras" (El Economista, 2012, párr. 1). De este modo, se evidencia la tendencia del mercado a siempre beneficiarse; los llamados a perder y ser sacrificados son los trabajadores. En el escenario planteado, las personas morirán muy ancianas trabajando, porque la edad para pensionarse será cada vez mayor, con lo cual el dios capital se ahorrará el pago de pensiones de gente "improductiva" para su sistema.

La situación de América Latina, evidencia que varios de los derechos humanos que estuvieron garantizados con los gobiernos de izquierda en áreas de la salud, educación, vivienda, empleo, luz, agua, han sido suprimidos, anulados y negados por parte de gran cantidad de gobiernos neoliberales. La mayor parte de estos derechos, en varios países, han sido privatizados; en nombre de la privatización y de la lucha contra las distorsiones del mercado, se organiza y se lleva a cabo la abolición sistemática de esos derechos, reconocidos en la Declaración Universal de Derechos Humanos, muchas veces incluso en nombre de la democracia. Así, se abandona la política social, la política del empleo, la política ambiental, la educación para todos, la seguridad para todos, la salud para todos, las pensiones dignas, etc.

La ideología neoliberal pretende hacer creer que todo lo anteriormente expuesto no puede ser de otra manera, esa falsa idea de que así funciona la democracia, recortando y negando derechos humanos se homogeniza, y se promueve una cultura política para aceptar esa falsa "democracia" (la democracia burguesa). Todo aquello que se aleje de su accionar y sus ideales será manipulado para crear la idea de que se trata de una dictadura; no se acepta otro mundo posible, un mundo donde los seres humanos sean prioridad y no el capital: quien pretenda un mundo así, será negado (bloqueado), demonizado, censurado, invisibilizado o, en el mejor de los casos, calumniado.

\section{Cuba y los derechos humanos}


En América Latina, cada vez que surge un gobierno que prioriza a los seres humanos por encima del capital, es objeto de campañas de descrédito por parte del gobierno de los Estados Unidos. En nombre de la democracia y los derechos humanos, se realizan bloqueos económicos, financieros, comerciales, mediáticos, agresiones armadas, campañas de desprestigio, demonización de sus dirigentes y calumnias contra sus políticas sociales, y este es acusado de dictadura. En primera instancia, lo hicieron contra Cuba -y lo siguen haciendo hasta el presente- cuya revolución empezó en 1959; después, fue contra el gobierno de la Unidad Popular en Chile, en 1970; continuaron con la revolución sandinista en Nicaragua en 1979; hoy lo hacen contra la revolución bolivariana en Venezuela, iniciada en 1998; y, más recientemente, el 10 de noviembre del 2019 apoyaron el golpe de Estado contra el presidente Evo Morales en Bolivia. El furor que desata el establishment contra estos procesos no tiene límites y ha logrado que mucha gente crea lo que ellos dicen sobre esos gobiernos, por lo cual las agresiones que comete Estados Unidos, desde su condición de país hegemónico, resultan justificadas, normalizadas y naturalizadas. Refiriéndose a la situación de Cuba, Gallardo (2007) dice: "Internacionalmente, la acentuación de las agresiones y del bloqueo contra Cuba resulta geopolíticamente democrática" (p.53).

El tema de los derechos humanos con respecto a Cuba ha sido manipulado por los Estados Unidos, comenzando con el gobierno de James Carter (1977-1981); Washington empezó a utilizar el tema en su política exterior como punta de lanza para imponer su esquema de dominación. De ahí en adelante, su uso por parte de las autoridades estadounidenses ha sido permanente hasta nuestros días y han logrado relacionar Cuba con la violación de los derechos humanos. Mientras que, por un lado, se acusa a Cuba de lo anterior, sin presentar pruebas, por otro lado, se mantiene en silencio las múltiples acciones relacionadas a la violación de derechos humanos en los países llamados democráticos:

Callan sobre la situación de los derechos humanos en países en los que con mucha frecuencia se asesinan a periodistas, aparecen fosas comunes con cientos de cadáveres, se práctica el crimen político, la ejecución extrajudicial, la desaparición forzosa, se reprimen las manifestaciones con gases lacrimógenos, armas de fuego y balas de goma, y hasta puede que jamás sus ciudadanos hayan votado en elecciones. (Ramírez y Romero, 2016, p.133)

O tal como afirma Hinkelammert, siempre en la perspectiva de la inversión de los derechos humanos:

También Guantánamo es un ejercicio del misterio del amor. En el campo de los derechos humanos hay que hacer un constante trabajo crítico frente al uso vergonzoso 
de los derechos humanos para violarlos. En Colombia se da todo el tiempo el problema. El anterior presidente colombiano, Álvaro Uribe, es un hombre de derechos humanos, igual que lo es Bush y lo fue Reagan. (Hinkelammert, 2012a, p.112)

¿Puede decirse entonces que a los Estados Unidos le interesa de verdad los derechos humanos? ¿Querrá un imperio como los Estados Unidos promover los derechos humanos en el mundo, los cuales ni siquiera están garantizados para sus propios ciudadanos?

A Cuba no se le permite tener derecho a su libre autodeterminación, no se le perdona ser independiente y soberana. Cuba es un símbolo de la libertad, libertad que no es aceptada por los Estados Unidos, hecho que explica por qué contra Fidel Castro se implementaron más de 638 intentos de asesinato. ¿Habrá mayor violación de los derechos humanos que un bloqueo económico, comercial y financiero contra un país? Refiriéndose a Cuba y a Fidel, cuando este vivía, Hinkelammert menciona:

la razón por la que Estados Unidos la tiene en la mira es por lo que representa en términos de símbolo de posible libertad: un gran peligro que debe ser eliminado es Fidel. La hipocresía del mundo consiste en no rechazar el bloqueo económico a Cuba. Fidel es acusado de dictador y eso es terrible, pero los bloqueos parecen no ser terribles, aunque son mecanismos tan inhumanos como los bombardeos. Siempre tienen el carácter de genocidio. El problema, entonces, no es ser inhumano; el problema es no estar al servicio del Imperio. (Hinkelammert, 2012a, p. 53)

Permanentemente el gobierno cubano es presentado al mundo como un monstruo que viola los derechos humanos de sus habitantes, el supuesto monstruo del comunismo que se debe combatir en nombre de los derechos humanos, y, aunque las agencias cablegráficas de Cuba hacen esfuerzos por mostrar los logros sociales alcanzados por la revolución en materia de educación, seguridad, salud, desarrollo humano, empleo, vivienda, deporte, cultura, etc., la mayoría de la gente sigue creyendo la versión que los Estados Unidos ha construido sobre Cuba. Por tal situación, no resulta sorpresivo que en las cuatro entrevistas más extensas realizadas a Fidel Castro por sus interlocutores (Gianni Miná, Frei Betto, Tomás Borge e Ignacio Ramonet) esté presente el tema de los derechos humanos; quisieron que se supiera sobre el tema en la voz del principal protagonista de la Revolución cubana.

Eduardo Galeano, refiriéndose al papel que desempeñan los medios de comunicación con respecto a la Revolución cubana, plantea: "contra Cuba se aplica una lupa inmensa que magnifica todo lo que ahí ocurre cada vez que conviene a los intereses enemigos...mientras la lupa se distrae y no alcanza a ver otras cosas importantes y que los medios de comunicación no hacen por informar" (Radio 
Uchile, 2010). Desinformar, ocultar, agredir, tergiversar, negar y calumniar todo lo que Cuba hace por los derechos, humanos a pesar del bloqueo, forma parte de la concepción invertida e interesada que tiene Occidente (el establishment burgués) sobre los derechos humanos, planteada por Estados Unidos. El gobierno que esté a favor de los derechos humanos y ponga a los seres humanos en primer lugar, antes del mercado, es culpado de abusar de los derechos humanos, se le denuncia de no ser democrático, de irrespetar la libertad de empresa, de ser una dictadura, o se le acusa de promover el terrorismo. "El occidente, que se jacta haber descubierto los derechos humanos, descubrió a la vez la manera más cruel e hipócrita de violarlos en nombre de estos mismos derechos humanos" (Hinkelammert, 2007, p.232).

Cuba, como cualquier otro país, tiene problemas, pero esto no debería ser razón para realizar valoraciones de la lucha que da el gobierno por asegurar los derechos de sus ciudadanos, ignorando que se trata de un país bloqueado, pobre y tercermundista, el cual, a pesar de esas condiciones socioeconómicas, mantiene alto los índices de calidad de vida:

En Cuba hay infinidad de problemas, a no dudarlo (como los hay en todas partes, por cierto. ¿Suecia no los tiene?). Una vez más, entonces, la pregunta: ¿dónde se vive mejor? Vale recordar que en el Norte próspero y desarrollado se habla de "calidad de vida"; en el Sur, pobre y oprimido, en todo caso se habla de su posibilidad. Cuba, con enormes problemas estructurales, bloqueada, agredida continuamente, tiene una cantidad de índices de calidad de vida similar a los países llamados desarrollados (esos que manejan los bancos del mundo, deciden las guerras e imponen las modas que estamos obligados a seguir). (Colussi, 2019, párr.26)

Es posible hablar de los logros de Cuba en materia de derechos humanos en diversas áreas: la protección de sus ciudadanos cuando se producen fenómenos como ciclones y huracanes (que son frecuentes); el acceso a medicamentos por medio de países terceros para superar el bloqueo al precio que sea necesario, con el fin de salvar la vida de los niños; la atención especializada a las personas con algún tipo de discapacidad; las políticas de atención a los ancianos (Cuba es uno de los países con mayor envejecimiento poblacional en América Latina y está previsto que el 2050 será uno de los mayores del mundo); los logros en esperanza de vida; la disminución de la mortalidad y desnutrición infantil; los bajos índices de desempleo; la democratización del acceso a la cultura; el desarrollo científico; el acceso al deporte; el desarrollo humano; el internacionalismo solidario; la estrategia para la protección ambiental; el país más seguro de la región con bajos índices de violencia y una evidente reducción de la criminalidad; la tasa de reclusos por habitantes es la más baja en América Latina, entre otros (Ramírez y Romero, 2016). 
Lo que Cuba ha logrado en relación con los derechos humanos en otras naciones merecería varios trabajos de investigación, los cuales, en caso de realizarse, contrastarían esa perspectiva invertida de los derechos humanos, ejemplo de esto, la lucha que han dado los médicos cubanos contra la epidemia del ébola en África, entre el 2014 y 2015; el programa Operación Milagro que ha realizado cirugías oftalmológicas a más de 3.4 millones de personas en 34 países; el programa de alfabetización "Yo sí puedo" que ha graduado a más de 9 millones de personas en el mundo, o la graduación en Cuba de más de 65000 estudiantes extranjeros.

En cuanto a participación política y democrática, un ejemplo esclarecedor fue la aprobación de su nueva Constitución en 2019, la cual, contra lo que se vaticinaba desde el exterior, participaron cerca de 9 millones de personas en los debates (de una población de 11 millones de habitantes) en más de 133681 reuniones a nivel de cuadra, donde se realizaron 1706872 intervenciones, de las que 783174 fueron propuestas (666 995 modificaciones, 32149 adiciones, 45548 eliminaciones y 38 482 dudas), más 2125 propuestas procedentes de cubanos residentes en el exterior; de esta forma, el país se convirtió en una asamblea constituyente (Cubadebate, 2018). Lo anterior demuestra que se trata de un país apasionado por la política y por la democracia participativa. Este fue uno de los ejercicios mayormente democráticos que difícilmente puede exhibir otra nación en el mundo.

Otro dato importante que mencionar es que, en Cuba, el $66 \%$ de profesionales son mujeres, igualmente el 53.2\% de los diputados (Nodal, 2018). Se trata de cifras que hablan bien de la participación y representación de una fuerza imprescindible de la población para garantizar el desarrollo próspero de la nación.

Aquí no es posible referirse a todos los logros obtenidos en derechos humanos de Cuba, por lo cual, el artículo se centrará en tres aspectos específicos: educación, salud e infancia.

Cuando se suelen realizar este tipo de revelaciones con respecto a Cuba, se activan los centros de poder de las democracias burguesas y neoliberales para descalificarlo, arguyendo que se trata de la "versión oficial cubana", incluso cuando la versión oficial cubana es verdadera. Ante esto, la información que aquí se expone no procede de los centros oficiales de documentación del gobierno cubano, sino que se basa en informes obtenidos de organismos internacionales pertenecientes a la ONU, evitando así que los datos señalados sean catalogados de izquierdistas o comunistas. 


\section{La educación en Cuba}

La Organización de las Naciones Unidas para la Educación, la Ciencia y la Cultu$\mathrm{ra}$, conocida internacionalmente como UNESCO, ejecuta visitas periódicas a los países miembros de la ONU y mantiene constantes monitoreos sobre la situación y el desarrollo de la educación. Su trabajo es de conocimiento público y se cuenta con suficiente información en su sitio oficial en la web.

Un informe sobre la educación en la región denominado "Cuba es el país de América Latina y el Caribe con mayor Índice en el Desarrollo de la Educación" (UNESCO, 2014) resulta revelador. Aunque la fuente es la UNESCO y no un órgano de prensa del gobierno cubano, el informe no recibe, ni recibió, titulares en medios burgueses, con lo cual, como "lo que no se publica, no existe", el hecho es desconocido para la mayoría de las personas (cabe preguntarse: ¿existe todo lo que la prensa burguesa dice?). Es difícil encontrar información veraz en los grandes medios de comunicación acerca de las conquistas sociales de Cuba debido a que "la lupa se distrae", sin embargo, cuando algo relacionado a esta información es publicado produce sorpresas:

Algo quedará en el cerebro después de tanta mentira para suponer que detrás de esas cifras hay una sociedad sin lujos, pero con las condiciones de alimentación, salubridad y educación en las familias, que no concuerdan con el cuadro de crisis absoluta que a diario los grandes medios de comunicación "pintan" sobre la Isla. (Sánchez, 2012, p.31)

Según el Informe de Seguimiento de la Educación para Todos en el Mundo 20132014 "Enseñanza y aprendizaje: Lograr la calidad para todos" (UNESCO, 2014), Cuba invierte en educación el 13\% del Producto Interno Bruto (PIB), y con un Índice en el Desarrollo de la Educación (IDE) de 0.983, lidera América Latina y el Caribe. Según Herman Van Hooff, director de la Oficina Regional de Cultura para América Latina y el Caribe de la UNESCO, la realidad de la educación en el mundo, a pesar de los avances de los últimos diez años, es que 57 millones de niños siguen sin estar escolarizados y 774 millones de adultos son analfabetos; entre estos datos no aparece ningún niño ni anciano cubanos.

Ese mismo año, Miguel Llivina Lavigne, representante de la Oficina regional de Cultura para América Latina y el Caribe de la UNESCO en el Congreso Internacional Universidad, sostuvo que "la educación cubana es un ejemplo para el mundo" y que el Î́ndice de Desarrollo de la Educación es muy elevado "incluso si se compara con los países desarrollados. El índice considera la calidad, la primera 
infancia, la primaria, los jóvenes, la alfabetización de los adultos y la paridad entre los sexos" (RT, 2014).

Recientemente, en una visita que realizó una misión internacional de la UNESCO a las escuelas de Cuba con el propósito de sistematizar las prácticas de educación para el desarrollo sostenible, Katherine Müller Marín, representante de la UNES$\mathrm{CO}$, felicitó a Cuba por buscar superar la calidad de la Educación con respecto a la Agenda 2030. Aunque Cuba es un modelo de excelencia en la educación, "mantiene un esfuerzo de continuo mejoramiento exitoso como es el caso del actual perfeccionamiento del sistema educacional cubano, que está siendo experimentado en más de 100 escuelas en todo el país" (UNESCO, 2018).

\section{La salud en Cuba}

La Organización Mundial de la Salud (OMS) es el organismo de la ONU encargado de gestionar políticas de prevención, promoción e intervención en salud a nivel mundial. En el boletín "Cuba: hacia una generación sin VIH" (OMS, 2016) señala que Cuba se convirtió el 2015 en el primer país del mundo en eliminar la transmisión materno infantil del VIH y de la bacteria causante de la sífilis como problemas de salud pública.

En la década de los ochenta, cuando se inició la epidemia de la infección del VIH, Cuba fue uno de los primeros países que implementó un programa de prevención y tratamiento. En 2001, este país desarrolló numerosos medicamentos genéricos para tratar dicha infección. Los fármacos antirretrovirales fueron el tratamiento cotidiano, siempre gratuitos para la población que los requería.

En 2013, Cuba solicitó a la OMS la validación de la eliminación de la transmisión materno infantil del VIH y la sífilis. Para lograr esto, el Ministerio de Salud Pública preparó un informe del país en 2014, el cual fue examinado por expertos independientes. En 2015, un equipo de peritos internacionales hizo una evaluación a nivel nacional y luego recomendaron validar la solicitud, la cual fue aprobada por un comité de 17 expertos externos que asesoran a la Sede de la OMS en esta área. Así, el 30 de junio de 2015, la OMS anunció que Cuba había dado este importante paso para librar del sida a la siguiente generación. Para su aprobación, la OMS solicitó que no solo debía generarse una reducción de la transmisión materno infantil del VIH, sino que el país debía demostrar su compromiso con las metas de eliminación, tener programas bien establecidos de salud materna e infantil y de lucha contra esta infección, además de contar con servicios fiables de laboratorio y con un sistema sólido de información sanitaria, y cumplir con los principios de la igualdad de género y de compromiso de la sociedad civil. 
Según los estudios realizados por la Organización Mundial de la Salud, publicados con el título "Cuba: hacia una generación sin VIH" (OMS, 2016), el éxito de Cuba en esta área es resultado de su sólida red de atención primaria que funciona a nivel nacional, 451 policlínicos comunitarios que son considerados el pilar fundamental del sistema y tratan la mayoría de los problemas de salud de la población, un consultorio donde atiende un médico en cada barrio y una enfermera de la familia, siempre cerca de la gente.

De acuerdo con el informe del Programa Conjunto de las Naciones Unidas sobre el VIH/SIDA (OMS, 2016), la apuesta de Cuba por la promoción de la salud y la atención primaria ha dado sus frutos; la prevalencia de la infección por el VIH en Cuba ha sido siempre la más baja en las Américas y ha estado entre las más bajas del mundo.

\section{La infancia en Cuba}

El Fondo de las Naciones Unidas para la Infancia o UNICEF (United Nations International Children's Emergency Fund) es una agencia de la ONU dedicada a proveer ayuda humanitaria y promover el buen desarrollo de niños y madres en países de Tercer Mundo. Según este organismo, Cuba alcanzó una tasa de mortalidad infantil por malformaciones congénitas de 1,0 por 1.000 nacidos vivos. Estados Unidos reporta 1,8; Japón, 1,5; Noruega, 1,7; Argentina, 3,6; y Chile 3,7 (Reuters, 2011).

De acuerdo con José Ortiz, representante de Unicef en la Isla, "Cuba es uno de los países donde la Convención sobre los Derechos del Niño tiene mayor vigencia, lo que significa que se han instaurado muchas políticas públicas que garantizan el desarrollo de los niños" (El Mundo, 2010, párr. 3). Tal y como expresa Sánchez (2012): "no solo es eso también hay ciencia detrás del resultado, el cual logra superar a los países del llamado Primer Mundo, convirtiendo la más alta tecnología en calidad de vida" (p.31).

María Cristina Perceval, directora regional de Unicef para América Latina y el Caribe, sostuvo en el foro "Derechos de la Niñez a crecer en una familia", llevado a cabo en marzo de 2018 en Managua, que "Cuba es campeón a nivel mundial en la promoción y protección de derechos de la niñez" (Telesur, 2018, párr. 1). Su afirmación se sustenta en los avances que Cuba ha obtenido en salud, prevención del embarazo adolescente, eliminación de la trasmisión materno-infantil del VIH/ SIDA en 2015 y en la preparación de la nación ante desastres naturales, cuyo objetivo es actuar con eficacia, profesionalismo y rapidez cuando las circunstancias lo requieran. 
En el presente, Cuba cuenta con el programa "Educa a tu hijo", un modelo mundial en el desarrollo infantil temprano; dicho programa promueve, desde hace 26 años, el rol protagónico de la familia en la formación de los menores, con un enfoque comunitario y multisectorial, y la felicidad de las niñas y niños como un interés primordial. La familia cubana es considerada la insustituible célula fundamental de la sociedad.

En junio de 2019, el II Congreso Internacional Neurociencias e Infancias realizado en Colombia, reconoció a Cuba con el Premio Especial Infancias 2019 por el buen desempeño de atención a la niñez en el sector salud (Razones, 2019).

Según el Informe sobre la Política Alimentaria Mundial en 2018, dado a conocer en la sede de la Organización de las Naciones Unidas para la Alimentación y la Agricultura (FAO), en Roma, Cuba es el quinto país entre los 14 primeros que han logrado reducir el índice del hambre y la desnutrición de manera sostenida por varios años: "aparece entre las naciones que más han avanzado en sus políticas alimentarias con igualdad y están más cercanos a la meta vinculada al Objetivo de Desarrollo Sostenible 2, con la aspiración de alcanzar cero hambre y desnutrición en 2030" (International Food Policy Research Institute, 2018, párr. 3). Aunque se trata de información brindada por una organización internacional de prestigio, el poder mediático se ha encargado de: "Demonizar a Cuba. Hacer que los niños de las escuelas españolas sientan lástima de los niños cubanos, escolarizados, saludables, como pocos de América Latina" (Ubieta, 2014, p.262).

Contrario a la visión invertida e interesada de los derechos humanos que posee Occidente, y a las historias inventadas y calumniosas contra la Revolución cubana, las organizaciones de la ONU ofrecen resultados científicos de los logros de este gobierno en educación, salud e infancia, pues no se trata de alcances menores de Tercer Mundo, sino que varios de ellos disputan primeros lugares con países primermundistas; todo en las condiciones de un país bloqueado, las cuales, como señalara Hinkelammert, son tan inhumanas como los bombardeos porque poseen el carácter de genocidio. Una vez más, como se ha expuesto a lo largo del texto, "la lupa se distrae" y no hace alusión al hecho de que el bloqueo económico le impide a Cuba tener acceso al comercio y a los créditos del principal mercado internacional, motivo por el cual los medios, desde hace varias décadas, comunican de forma manipulada que el socialismo es un fracaso económico. Hinkelammert es contundente cuando afirma que "el mundo nunca menciona que el verdadero problema de los derechos humanos en Cuba es Guantánamo. Cada vez se habla menos de la tortura sistemática, de la destrucción sistemática de la identidad de personas concretas" (2012a, p.53). La Base Naval de Guantánamo es una instalación ilegal en el territorio de Cuba, ocupada por los Estados Unidos desde 1903 
en contra de la voluntad del pueblo cubano; ahí el gobierno de los Estados Unidos, desde 2002, abrió una cárcel con el objetivo de acoger a extranjeros detenidos por terrorismo tras los atentados a las Torres Gemelas el 11 de septiembre de 2001.

El canal de televisión internacional Hispan TV (2018), en uno de sus reportajes sobre la Isla, señala los efectos que ha tenido el bloqueo en todos los sectores de la vida de la población cubana; este resulta revelador cuando se refiere al tratamiento de niños con cáncer: cada año, entre 300 y 400 niños pacientes de cáncer de distintas zonas del país, son atendidos sin costo alguno en el Instituto Nacional de Oncología y Radiobiología de La Habana (INOR), aunque en ocasiones las sanciones económicas norteamericanas contra Cuba se imponen en el camino. En el último año han existido casos de pacientes con tumores del sistema nervioso central de alto grado que se han visto afectados por la carencia de la Temozolomida, fármaco de primera línea principalmente producido en Estados Unidos.

Otro programa médico afectado por esta política trabaja para salvar los miembros inferiores en niños con cáncer de huesos a través de endoprótesis extensibles. Tras la llegada al poder de Donald Trump y, con esto, un significativo retroceso en las relaciones entre Washington y La Habana, el bloqueo se ha intensificado, limitando así las posibilidades de Cuba para obtener cualquier tipo de instrumental o fármaco norteamericano.

\section{Conclusiones}

A lo largo del presente artículo, ha sido posible diferenciar al menos dos perspectivas para abordar los derechos humanos. En primera instancia, la visión creada por Occidente que responde a los intereses de una burguesía capitalista que posee como prioridad la propiedad privada, por encima del ser humano, basada en una perspectiva invertida de los derechos humanos; esta visión tiene hoy su mayor expresión con el neoliberalismo, el cual, sobre el andamiaje de la democracia burguesa, desarrolla y aplica la economía de mercado que niega, reduce, elimina, rechaza y viola los derechos de los humanos de la población. Dicha situación a lo largo de la historia, en particular en los gobiernos neoliberales más recientes de América Latina, ha generado que los diversos movimientos sociales, en sus diferentes expresiones concretas, se organicen para luchar contra estas políticas económicas abusivas que atentan contra sus derechos. Como muestra de esto, se evidencian las luchas de los campesinos, los defensores del medio ambiente, las mujeres, los indígenas, los obreros, los educadores, el sector de la salud, los estudiantes, los afrodescendientes, las poblaciones LGBTIQ+, los sin tierra, los sintecho, entre otras. 
El mundo está configurado con esta visión invertida de los derechos humanos y, por ende, desde países hegemónicos como los Estados Unidos que posee respaldo de los defensores del neoliberalismo y de los grandes medios de comunicación, y lleva a cabo, desde hace muchos años, agresiones económicas, políticas, comerciales, financieras y mediáticas contra todo aquel que se oponga o resista a tal configuración de mundo; desde esta percepción, no se acepta otra perspectiva que no sea la de la formulación invertida de los derechos humanos.

La segunda perspectiva, denominada por Hinkelammert como la prioridad por la dignidad humana, mantiene que solo las personas poseen derechos humanos. En cambio, la propiedad y las instituciones carecen de estos. Cuba es un caso en donde se prioriza la dignidad humana por encima de la propiedad y el lucro; la Revolución trabaja por asegurar los derechos humanos de sus ciudadanos y de muchas personas fuera de sus fronteras (ellos no viven exhibiendo esos hechos). Aunque los resultados son ocultados, invisibilizados, tergiversados o calumniados por el establishment, las entidades internacionales pertenecientes a la Organización de las Naciones Unidas, con personal científico y calificado, han reconocido en múltiples ocasiones tales logros.

\section{Referencias}

Adelaja, T. (2020). Coca-Cola pagó a científicos para que minimizaran la influencia de las bebidas azucaradas en la obesidad. https://actualidad.rt.com/ actualidad/362367-coca-cola-pago-cientificos-azucaradas-obesidad

Así Estamos. (2018, 23 de noviembre). ¿Será Nayib Bukele de Izquierda Radical? [Video]. YouTube. https://www.youtube.com/watch?v=b8_Xjb6TLfo

Benites, A. (2018). La máquina de las 'fake news' trabaja a favor de Bolsonaro en Brasil. https://elpais.com/internacional/2018/09/26/actualidad/1537997311_859341.html

Betto, F. (2019). Posdemocracia. http://www.iade.org.ar/noticias/posdemocracia

Borges, G. (2019). Rafael Correa en entrevista con Misión Verdad: Todos tenemos que estar preparados para la traición. http://misionverdad.com/entrevistas/entrevista-correa

Borón, A. (2019). El hechicero de la tribu. Mario Vargas Llosa y el liberalismo en América Latina. Ediciones Akal.

CB24. (2013, 19 de noviembre). "Centroamérica Habla" con los candidatos opositores a la presidencia de Costa Rica (2/5) [Video]. YouTube. https://www.youtube.com/ watch? $=$ crcrmW8py $2 \mathrm{~s}$ 
CEPAL. (2017). Panorama Social de América Latina. https://repositorio.cepal.org/bitstream/ handle/11362/42716/7/S1800002_es.pdf

Colussi, M. (2019). En Cuba se puede caminar tranquilo por la calle. https://www.alainet. org/es/articulo/201040?utm_source=email\&utm_campaign=alai-amlatina

Cubadebtae. (2018). Presentan a los diputados resultados de la consulta popular del Proyecto de Constitución. http://www.cubadebate.cu/noticias/2018/12/18/presentan-cambios-en-el-proyecto-de-constitucion-derivados-de-la-consulta-popular/\#.XxfI6J4zbIU

El Confidencial. (2018). Un 97\% de fake news en Whatsapp: ¿campaña coordinada para que gane Bolsonaro? https://www.elconfidencial.com/mundo/2018-10-25/ jair-bolsonaro-fake-news-elecciones-brasil_1635334/

El Economista. (2012). El FMI recomienda elevar la edad de jubilación y reducir las pensiones. https://www.eleconomista.es/economia/noticias/3886868/04/12/2/FMILos-costes-del-envejecimiento-podrian-crecer-un-50-por-ciento-antes-de-2050.html

El Mundo. (2010). La tasa de mortalidad infantil en Cuba, inferior a la de EEUU, según UNICEF. https://www.elmundo.es/america/2010/04/25/cuba/1272206759.html

Fernández, C. (2019). Sinceramente. Sudamericana.

Gallardo, H. (2005). Siglo XXI, militar en la izquierda. Editorial Arlekin.

Gallardo, H. (2007). Democratización y democracia en América Latina. Ediciones Desde Abajo.

García, A. (2018. El vicepresidente boliviano Álvaro García Linera dio hoy una verdadera clase magistral sobre el futuro de las izquierdas y los retos por delante, en la cual dejó profundas reflexiones. http://misiones.minrex.gob.cu/es/articulo/ el-vicepresidente-boliviano-alvaro-garcia-linera-dio-hoy-una-verdadera-clase-magistral

Gobierno de Perú. (2003). Informe Final de la Comisión de la Verdad y Reconciliación. Anexo 3. http://cverdad.org.pe/ifinal/index.php

Guzmán,A.(2018).PeñaNieto deja crisis histórica en materia de derechos humanos. https://news. culturacolectiva.com/mexico/derechos-humanos-en-crisis-durante-sexenio-de-pena/

Hinkelammert, F. (Comp.). (1999). El huracán de la globalización. DEI.

Hinkelammert, F. (2007). Hacia una crítica de la razón mítica. El laberinto de la modernidad. Materiales para la discusiónEditorial Arlekín. 
Hinkelammert, F. (2012a). Lo indispensable es inútil. Hacia una espiritualidad de la liberación. Editorial Arlekín.

Hinkelammert, F. (2012b). Solidaridad o suicidio colectivo. Editorial Arlekín.

Hinkelammert, F. (Coord. y Ed.). (2017). La religión neoliberal del mercado y los derechos humanos. Editorial Arlekín.

Hinkelammert, F. (2018). Totalitarismo del mercado. El mercado capitalista como ser supremo. Editorial Akal.

Hispan T. V. (2018). Bloqueo de EE. UU. impacta negativamente en la salud cubana. https://www.hispantv.com/noticias/cuba/390747/bloqueo-eeuu-ninos-cancer-trump-salud

International Food Policy Research Institute. (2018). Cuba entre los países con menor índice de hambre y desnutrición. https://reliefweb.int/report/cuba/ cuba-entre-los-pa-ses-con-menor-ndice-de-hambre-y-desnutrici-n

Keith, G. (2017). ¿Dónde están los 500 mil empleos que ofrecieron con el TLC? http://www.periodicolibertad.org/2017/05/22/donde-estan-los-500-mil-empleos-que-ofrecieron-con-el-tlc/

NODAL. (2018). El nuevo Parlamento cubano es el segundo en el mundo con mayor presencia de mujeres. https://www.nodal.am/2018/04/el-nuevo-parlamento-cubano-es-el-segundo-en-el-mundo-con-mayor-presencia-de-mujeres/

NODAL. (2020). Al menos 573 líderes sociales fueron asesinados durante el gobierno de Duque. https://www.nodal.am/2020/07/al-menos-573-lideres-sociales-fueron-asesinados-en-lo-que-va-del-gobierno-de-ivan-duque-segun-indepaz/

Organización Mundial de la Salud. (2016). Cuba: Hacia una generación sin VIH. https:// www.who.int/bulletin/volumes/94/12/16-021216/es/

Pc peruano. (2016, 27 de marzo). Aldo Mariategui vs Veronika Mendoza tuvieron un tenso diálogo durante entrevista [Video]. YouTube. https://www.youtube.com/ watch?v=usDS39JiDCE

Radio Uchile. (2010). Eduardo Galeano: Se mira a Cuba "con una lupa que magnifica todo lo que interesa a sus enemigos". https://radio.uchile.cl/2010/03/23/eduardo-galeanose-mira-a-cuba-con-una-lupa-que-magnifica-todo-lo-que-interesa-a-sus-enemigos/

Rafael Correa. (2017, 17 de abril). Rafael Correa destroza a Jorge Ramos [Video]. YouTube. https://www.youtube.com/watch?v=jZoT4wcjkO0

Ramírez, E. y Romero, R. (2016). 5 temas polémicos sobre Cuba. Ocean Sur. 
Razones. (2019). Cuba obtiene el Premio Especial Infancias 2019, por atención a la niñez en materia de salud. http://razonesdecuba.cubadebate.cu/noticias/cuba-obtiene-el-premio-especial-infancias-2019-por-atencion-a-la-ninez-en-materia-de-salud/

Resumen Latinoamericano. (2019). Pensamiento crítico. Entrevista a Enrique Dussel. "La ecología debiera ser la medicina que trate la gran enfermedad de la tierra: La destrucción ecológica". http://www.resumenlatinoamericano.org/2019/07/01/pensamiento-critico-enrique-dussel-la-ecologia-debiera-ser-le-medicina-que-trate-la-gran-enfermedad-de-la-tierra-la-destruccion-ecologica/

Reuters. (2011). Cuba logra la menor mortalidad infantil de toda su historia. https://www.americaeconomia.com/politica-sociedad/sociedad/ cuba-logra-la-menor-mortalidad-infantil-de-toda-su-historia

Robin, M. (2013). Comemos veneno: "El cáncer, la infertilidad y la diabetes son por la comida". https://www.elconfidencial.com/alma-corazon-vida/2013-06-11/comemos-veneno_200291/?fbclid=IwAR2rASCynlBScZCH-hVzLzqfaEJ4NT5YQRkYDv8Ts9c3zNDKjcMpnoKwrXg

RT.(2013). Nobel demedicina: “Curarenfermedadesnoes rentablepara las farmacéuticas”. https://actualidad.rt.com/actualidad/view/93667-nobel-medicina-enfermedades-farmaceuticas-roberts

RT. (2014). Unesco: “La educación cubana es un ejemplo para el mundo”. https://actualidad. rt.com/actualidad/view/119953-unesco-educacion-cubana-ejemplo-mundo

Saccone, V. (2018). Un 97\% de fake news en WhatsApp: ¿Campaña coordinada para que gane Bolsonaro? https://www.elconfidencial.com/mundo/2018-10-25/ jair-bolsonaro-fake-news-elecciones-brasil_1635334/

Sánchez, I. (2012). Sospechas y disidencias. Una mirada cubana en la red. Casa Editora Abril.

Sputnik. (2018). Izquierda en Latinoamérica sacó a 72 millones de la pobreza, dice vicepresidente boliviano. https:/www.elpais.cr/2018/11/20/izquierda-en-latinoamerica-saco-a-72-millones-de-la-pobreza-dice-vicepresidente-boliviano/

Telesur. (2018). Unicef: Cuba es campeón en derechos de la niñez. https://www.telesurtv. net/news/unicef-cuba-defiende-derechos-ninos-20180312-0032.html

Ubieta, E. (2014). Ser, parecer, tener. Casa Editorial Abril.

UNESCO. (2014). Cuba es el país de América Latina y el Caribe con mayor índice en el desarrollo de la educación. http://www.cubadebate.cu/noticias/2014/02/01/unescocuba-es-el-pais-de-al-y-el-caribe-con-mayor-indice-en-el-desarrollo-de-la-educacion/\#. XyYcwCgzbIU 
UNESCO. (2014). La crisis mundial del aprendizaje tiene un costo anual de 129.000 millones de dólares. http://www.unesco.org/new/es/media-services/single-view/news/ global_learning_crisis_is_costing_129_billion_a_year/

UNESCO.(2018).UNESCO:Cubaesunejemplomundialdemejoresprácticas eneducaciónparael desarrollo sostenible. http://www.unesco.org/new/es/media-services/single-view-tv-release/ news/unesco_cuba_es_un_ejemplo_mundial_de_mejores_practicas_en

Univisión Noticias. (2018, 9 de marzo). ¿Admiraba Gustavo Petro a Hugo Chávez? Esta fue la respuesta del aspirante presidencial colombiano [Video]. YouTube. https://www. youtube.com/watch?v=WWVA3GyV68A

Univisión Noticias. (2018, 2 de abril). ¿Enjuiciaría a Peña Nieto? ¿Son Maduro y Castro dictadores? Así respondió el candidato López Obrador [Video]. YouTube. https://www. youtube.com/watch? $=$ FsCdYbSCXCU

Vargas, M. (2018). La llamada de la tribu. España: Alfaguara. 
